\title{
As Políticas de Atenção à Infância e Juventude no Município de Volta Redonda: um Mapeamento das Instituições Inscritas no Conselho Municipal dos Direitos da Criança e do Adolescente
}

\author{
Professora Mestra Mônica Santos Barison (Ciências Sociais Aplicadas - UniFOA) - \\ monica.barison@foa.org.br
}

\section{Resumo}

Este artigo objetiva a apresentação dos dados quantitativos e qualitativos obtidos a partir de pesquisa de campo realizada no ano de 2005. Tal atividade acadêmica esteve vinculada ao Programa de Iniciação Cientifica do UniFOA, através do Curso de Serviço Social. A pesquisa mapeou as políticas sociais existentes, nos campos da saúde e assistência social, dirigidas a população infanto-juvenil do município de Volta Redonda. Verifica-se que as políticas sociais têm se constituído como espaços sócio-ocupacionais de diferentes profissionais da área das ciências sociais, em específico do assistente social.Os dados da pesquisa contribuem, então, para a produção de conhecimento acerca da realidade destas políticas, na perspectiva de favorecer a qualificação da intervenção profissional. Outrossim, os dados explicitam a relação existente entre as diretrizes/ princípios preconizados pelo Estatuto da Criança e do Adolescente (Lei que regulamenta a matéria) e o modo como as políticas sociais se organizam na contemporaneidade.

Palavras chave: Políticas Sociais; Direitos da Criança e do Adolescente; Rede de Serviços; Município de Volta Redonda.

\section{Os objetivos e a relevância da pesquisa}

É sabido que, no campo das políticas de atenção à população infanto-juvenil no Brasil, desde a Promulgação do Estatuto da Criança e do Adolescente em 1990 (ECA), novos princípios se apresentam como referência para a implantação de projetos e programas nesta área.

Fundamentada na Doutrina de Proteção Integral, a Lei determina dentre outros, a redefinição do "status" que a criança e o adolescente ocupam na sociedade; a redefinição do papel do Estado, da sociedade civil e da família, na perspectiva de garantia dos direitos desta parcela da população.

Entretanto, se mudanças foram levadas a cabo no plano legal, a expectativa é a de que fossem produzidas alterações significativas no conjunto das relações sociais que materializam o cuidado com a infância e juventude.

Neste sentido, consideramos que a dicotomia possivelmente existente entre a letra legal e o modo como as políticas sociais efetivamente se (des) organizam, deve ser 
evidenciada como objeto de análise, na perspectiva de construção de subsídios para alteração desta realidade e, conseqüentemente, para a aplicação dos dispositivos previstos em lei.

Frente a este perspectiva de análise, a pesquisa, intitulada "Políticas de Atenção a Criança e ao Adolescente no Município de Volta Redonda", traçou como objetivo o mapeamento das políticas de atenção à criança e ao adolescente no município de Volta Redonda, nos campos da assistência social e saúde, na perspectiva de conhecer a rede de serviços disponíveis para o segmento da população infanto-juvenil neste território.

O universo da pesquisa se constituiu de instituições cadastradas no Conselho Municipal dos Direitos da Criança e do Adolescente (CMDCA) da cidade.

O interesse para a realização da pesquisa foi construído a partir dos debates travados na disciplina "oficina de supervisão", disciplina esta que oferece supervisão acadêmica para alunos inseridos nos mais diversos campos de estágio em Serviço Social.

As observações empíricas dos discentes (vinculadas as mais diversas experiências vividas no campo de estágio, que são apresentadas em sala de aula); os estudos dirigidos sobre os princípios e diretrizes previstos no Estatuto da Criança e do Adolescente relacionados às políticas sociais; as análises sobre as inúmeras situações de risco pessoal e social a que estão submetidas crianças e adolescentes no Brasil; os estudos sobre o significado histórico das políticas sociais na sociedade brasileira e ainda sobre a inserção do Serviço Social nestas políticas se constituíram como temas fundamentais para a produção, por parte dos alunos e dos professores, de inquietações e reflexões acerca da (des) organização e (in) eficácia das políticas sociais destinas ao segmento infanto-juvenil no território de trabalho onde se estava inserido.

O projeto de iniciação cientifica apareceu, então, como possibilidade de aglutinar e sistematizar este debate, reconhecendo a pesquisa como importante instrumento para o "desvelamento" da realidade social.

Compreendendo a pesquisa social como eixo fundante da formação em serviço social, esta atividade em específico, articulada ao ensino do trabalho profissional (materializado na disciplina “oficina de supervisão”), assumiu ainda como objetivo possibilitar o aprendizado dos alunos ao que se refere à produção de conhecimento para a análise dos elementos constitutivos do trabalho do assistente social. A intervenção qualificada deste pressupõe, dentre outros, a capacidade de análise crítica das mais diversas expressões da questão social (matéria-prima de seu trabalho) e ainda a análise da organização das políticas sociais (que determinam os meios de seu trabalho).

Na perspectiva de desenvolver o referido projeto de iniciação cientifica, formou-se um grupo composto por alunos pesquisadores, que se propôs reunir sistematicamente para estudo de bibliografia referente ao tema da pesquisa, montagem do questionário e treinamento para aplicação do mesmo. Tais atividades eram supervisionadas pelo professor responsável pelo projeto.

Entretanto, no momento da realização da pesquisa de campo propriamente dita, verificou-se a necessidade e possibilidade de ampliar a participação de outros alunos, que estavam vinculados à disciplina "oficina de supervisão". Foi avaliado, junto aos outros professores, que a pesquisa poderia ser reconhecida como atividade da disciplina, tendo em vista que esta objetiva a construção de atitude investigativa do estagiário de serviço social.

Assim, o projeto de iniciação cientifica articulou-se às atividades de ensino, que favoreceu a realização da pesquisa de campo.

Vale destacar que quarenta e quatro alunos (quinto e sexto período do curso) realizaram a pesquisa, através da aplicação do questionário. Elaboraram ainda relatórios parciais, que serviram de base para elaboração deste material.

Os alunos, em grupo ou individualmente, devidamente identificados (através de carta de apresentação fornecida pela Instituição de Ensino), inicialmente, estabeleceram contato 
com a instituição a fim de apresentar a proposta da pesquisa, solicitar autorização para realização da mesma e agendar visita. Posteriormente, no dia previamente agendado, o questionário foi aplicado.

O questionário foi utilizado como instrumento da pesquisa, sendo composto de perguntas abertas e fechadas.

\section{Os Dados Obtidos}

O Conselho Municipal de Defesa da Criança e do Adolescente de Volta Redonda, segundo o cadastro disponibilizado, possui 41 instituições inscritas. Dentre estas, 14 possuem assento no referido órgão (sendo mantida a paridade entre entidades governamentais e nãogovernamentais, prevista em lei para a formação do mesmo).

Ressalta-se que seis das instituições cadastradas não foram consideradas como alvo de estudo, tendo em vista os objetivos da pesquisa (destas, quatro entidades oferecem serviços no campo da educação e não da assistência social ou saúde; uma representa um Conselho de profissionais e não presta serviços diretos a população e a outra se localiza em município vizinho).

A pesquisa foi realizada, então, em trinta e cinco destas instituições. Destaca-se que, deste universo, constatou-se, segundo relato de seus membros, que duas instituições não estão funcionando atualmente; outras duas não mais desenvolvem trabalhos com crianças e adolescentes.

Ainda neste universo, não foi possível realizar a pesquisa em oito instituições, pois não se obteve sucesso no processo de estabelecimento de contato com os seus respectivos responsáveis ou mesmo não houve disponibilidade de algumas das instituições para recebimento dos pesquisadores. Vale destacar a existência de prazo pré-determinado para a realização da pesquisa de campo, o que impossibilitou a construção de diferentes estratégias para viabilização de acesso a estas instituições para a concessão das entrevistas.

Assim, os dados obtidos nesta pesquisa estão relacionados à realidade de 23 instituições cadastradas no Conselho. Destas, quatro se constituem como política pública municipal e 19 se caracterizam como entidades não governamentais.

Tendo em vista as especificidades da constituição histórica de cada um destes campos (governamental e não-governamental), que imprimem características diferenciadas ao modo de organização destas instituições, optou-se, para a apresentação dos dados, levar em consideração esta natureza organizativa de tais políticas.

Neste sentido, serão apresentados, inicialmente, os dados referentes às entidades não-

governamentais e, posteriormente, as governamentais. Ao final, serão feitas algumas considerações, que se constituem analise qualitativa dos dados obtidos.

A listagem das instituições que participaram da pesquisa encontra-se explicitado ao fim este artigo.

\subsection{As Organizações não-governamentais}

Conforme relatado anteriormente, o universo pesquisado se constituiu de 19 entidades não-governamentais.

Em relação à abrangência de atuação destas instituições, 12 entrevistados declararam que a instituição a qual pertence atende a população de toda a extensão do município de Volta Redonda; 05 informaram que a entidade possuiu caráter regional (atende municípios circunvizinhos) e 02 pontuaram que prestam serviços apenas a bairros específicos da cidade. 
Constata-se, segundo os entrevistados, que 08 entidades funcionam há mais de 15 anos no município; 02 existem entre 11 e 14 anos; 07 funcionam de 07 a 10 anos e 02 desenvolvem seus projetos a menos de 05 anos. Observa-se que 57,8\% das instituições não-governamentais do município foram inauguradas após a promulgação do Estatuto da Criança e do Adolescente, datada de 1990.

Sobre as linhas de ação da política de atendimento dirigidas à população infantojuvenil (regulamentadas pelo artigo 87 do Estatuto da Criança e do Adolescente), 08 entrevistados declararam que suas respectivas instituições desenvolvem políticas de assistência social; 06 informaram que desenvolvem políticas de assistência social e ainda políticas sociais básicas no campo da educação (creche); 02 responderam que implementam políticas sociais básicas no campo da saúde (dependência química) e também da assistência social; 02 identificaram que suas instituições assumem como linhas de ação as políticas sociais básicas (saúde e educação) e ainda a política de assistência social e 01 situa sua linha de ação apenas no campo das políticas básicas de saúde.

Vale destacar que nenhuma das entidades pesquisadas declarou que assume como linha de ação de suas políticas os "serviços especiais de prevenção e atendimento médico e psicossocial às vitimas de negligencia, maus-tratos, exploração, abuso, crueldade $e$ opressão" ou "serviços de identificação e localização de pais, responsável, crianças e adolescentes desaparecidos" ou ainda "proteção jurídico-social por entidades de defesa dos direitos da criança e do adolescente”. Tais linhas de ação também são regulamentadas no artigo 87 do ECA.

Em relação ao regime de atendimento (previsto no artigo 90 do ECA), o regime "orientação e apoio sócio-familiar" é identificado por 11 instituições como um dos que caracterizam os serviços prestados; o regime “apoio sócio-educativo em meio aberto" por 12 instituições e o “abrigo" por uma instituição.

Na perspectiva de identificar o seu público-alvo, os 19 entrevistados afirmam que seus serviços são ofertados para, prioritariamente, para a população infanto-juvenil advinda das classes subalternizadas. Em relação à faixa etária, constata-se que 08 entidades atendem crianças e adolescentes, independente da idade; 06 prestam serviço apenas a crianças; 03 atendem somente adolescentes; e 02 oferecem atendimento a crianças e adolescentes, porém limitando a idade. Em relação ao sexo, 18 instituições atendem meninos e meninas e uma considera como publico alvo somente a população masculina.

Variados foram os objetivos gerais citados pelos entrevistados no momento de identificar a finalidade de suas respectivas instituições. Assim, a tabela abaixo apresenta os principais objetivos apresentados, sendo quantificado a sua incidência no conjunto das respostas obtidas.

\begin{tabular}{|c|c|}
\hline Objetivos & Incidência \\
\hline Ajudar o próximo, atender a população carente & 07 \\
\hline $\begin{array}{l}\text { Oferecer cuidado e proteção para crianças cujos } \\
\text { responsáveis trabalham }\end{array}$ & 06 \\
\hline Oferecer tratamento de saúde & 04 \\
\hline Reabilitar portadores de deficiência & 02 \\
\hline Oferecer orientação espiritual & 02 \\
\hline Servir a Comunidade & 02 \\
\hline $\begin{array}{c}\text { Oferecer tratamento a crianças/adolescentes } \\
\text { dependentes químicos }\end{array}$ & 02 \\
\hline Profissionalizar o adolescente & 02 \\
\hline Promover o desenvolvimento social & 01 \\
\hline $\begin{array}{c}\text { Promover harmonização psíquica e crescimento } \\
\text { individual }\end{array}$ & 01 \\
\hline $\begin{array}{l}\text { Proteger as crianças e adolescentes vítimas de maus- } \\
\text { tratos }\end{array}$ & 01 \\
\hline
\end{tabular}




\begin{tabular}{|c|c|}
\hline $\begin{array}{c}\text { Promover inserção social, cultura e educacional da } \\
\text { criança e do adolescente }\end{array}$ & 01 \\
\hline Prevenir a desnutrição infantil & 01 \\
\hline Gerar emprego e renda & 01 \\
\hline Promover a cidadania & 01 \\
\hline $\begin{array}{c}\text { Oferecer abrigo a crianças e adolescentes em situação } \\
\text { de risco pessoal ou social }\end{array}$ & 01 \\
\hline $\begin{array}{c}\text { Cumprir as determinações do Estatuto da Criança e do } \\
\text { Adolescente }\end{array}$ & 01 \\
\hline
\end{tabular}

Tabela de no 1 - Pesquisa "As Políticas de Atenção à infância e juventude no Município de Volta Redonda: um mapeamento das instituições inscritas no Conselho Municipal dos Direitos da Criança e do Adolescente”

Ao que se refere à articulação das entidades, 14 entrevistados afirmam que suas respectivas instituições mantêm parcerias com outras entidades. Deste universo, verifica-se que 09 entrevistados identificam que tais parcerias se situam no campo do financiamento de recursos materiais ou humanos. Os outros 05 entrevistados citam que suas parcerias com outras instituições acontecem nos momentos que realizam encaminhamentos da população atendida para os diversos serviços, na perspectiva de atender as diferentes demandas que lhes são apresentadas. Vale destacar que 03 entrevistados declararam que suas instituições não estabelecem nenhum tipo de parceria. Em dois casos não se obteve resposta para o quesito.

Sobre a relação estabelecida com o Conselho Tutelar (órgão responsável em zelar pelos direitos das crianças e adolescentes), a incidência de respostas está apresentada na tabela abaixo. Ressalta-se que a pergunta formulada no questionário foi do tipo aberta, podendo o entrevistado discorrer livremente sobre o tema proposto.

\begin{tabular}{|c|c|}
\hline Relação com o Conselho Tutelar & Incidência \\
\hline $\begin{array}{c}\text { Recebe encaminhamento de casos do Conselho } \\
\text { Tutelar }\end{array}$ & 11 \\
\hline Encaminha casos para o Conselho Tutelar & 06 \\
\hline $\begin{array}{c}\text { Não recebe encaminhamento de casos do Conselho } \\
\text { Tutelar }\end{array}$ & 02 \\
\hline Não encaminha casos para o Conselho Tutelar & 02 \\
\hline Não existe nenhum tipo de relação & 02 \\
\hline Contato é informal & 01 \\
\hline Existe espaço para discussão de casos & 01 \\
\hline Sem dados & 05 \\
\hline
\end{tabular}

Tabela de $\mathbf{n}^{0} 2$ - Pesquisa “As Políticas de Atenção à infância e juventude no Município de Volta Redonda: um mapeamento das instituições inscritas no Conselho Municipal dos Direitos da Criança e do Adolescente”

Em relação à participação das entidades no Conselho Municipal dos Direitos da Criança e do Adolescente (órgão responsável pela política de atenção à população infantojuvenil), verificamos que, das 12 instituições não governamentais que não tem assento no Conselho, seis dos entrevistados afirmam que nenhum membro da instituição participa das Assembléias do referido órgão; quatro afirmam que participam, através da pessoa do Presidente da entidade. Vale destacar que em dois casos não obtivemos registro da resposta em relação a este item.

Os entrevistados forneceram dados sobre a origem do financiamento e ainda sobre a sustentabilidade das entidades.

Assim, observa-se o seguinte panorama: 


\begin{tabular}{|c|c|c|}
\hline Tipo de Recursos & $\begin{array}{c}\text { Fonte de } \\
\text { Financiamento }\end{array}$ & Quantidade de Instituições \\
\hline \multirow{6}{*}{ Materiais } & Federal & 05 \\
\hline & Estadual & 03 \\
\hline & Municipal & 05 \\
\hline & Internacional & 03 \\
\hline & Empresas & 03 \\
\hline & Doações/Sócios & 08 \\
\hline Tipo de Recursos & $\begin{array}{c}\text { Fonte de } \\
\text { Financiamento }\end{array}$ & Quantidade de Instituições \\
\hline \multirow{7}{*}{ Humanos } & Federal & 01 \\
\hline & Estadual & 01 \\
\hline & Municipal & 06 \\
\hline & Internacional & 02 \\
\hline & Doações/Sócios & 04 \\
\hline & Empresas & 02 \\
\hline & Voluntariado & 06 \\
\hline
\end{tabular}

Tabela de n⿳0 3 - Pesquisa “As Políticas de Atenção à infância e juventude no Município de Volta Redonda: um mapeamento das instituições inscritas no Conselho Municipal dos Direitos da Criança e do Adolescente"

Das entidades que recebem financiamento dos governos federal, estadual e/ou municipal, 06 entrevistados responderam que o repasse da verba é realizado de forma direta (tendo em vista existência de convênio); 05 responderam que o repasse é feito através do Fundo Municipal. Vale destacar que destes últimos, quatro dos entrevistados pertencem a entidades que possuem assento no Conselho Municipal dos Direitos das Crianças e Adolescentes.

Em relação a sustentabilidade da instituição, ou seja, da fonte de recurso que garante o funcionamento da entidade, 11 entrevistados afirmam que a sua instituição se mantém a partir das doações e/ou da arrecadação de verbas junto aos seus sócios; 03 com financiamento do governo municipal; 02 com financiamento de empresas; 02 com financiamento internacional; 01 com financiamento do governo estadual e uma com financiamento do governo federal.

\subsection{As Organizações Governamentais}

Registra-se que quatro das cinco instituições governamentais, que desenvolvem políticas especificas de atenção à população infanto-juvenil no campo da saúde e assistência social, se constituíram como universo da pesquisa.

Observa-se que as ações destas instituições pesquisadas fazem parte da organização de políticas sociais municipais levadas a cabo por três Secretarias e uma Fundação, que as implementam.

Em relação ao tempo de funcionamento de programas e projetos específicos que são dirigidos a crianças e adolescentes, 03 dos entrevistados responderam que a entidade funciona de 06 a 12 anos e 01 afirmou que a entidade possui mais de 15 anos.

A abrangência destas instituições é municipal. Dois dos entrevistados afirmam a existência de uma política descentralizada, que organiza a execução de programas e projetos segundo o grau de complexidade de seus objetivos e ainda segundo a demanda identificada nos diferentes bairros da cidade. 
Duas das instituições pesquisadas possuem como linha de ação a implementação de políticas sociais básicas (em especifico esporte e cultura) as outras duas implementam política de assistência social.

Uma instituição oferece regime de abrigo para a população atendida. As outras três oferecem os regimes de "orientação e apoio sócio-familiar" e ainda de "apoio sócioeducativo em meio aberto".

Diferentes programas e projetos atendem diversos segmentos da população infantojuvenil (vide listagem anexa), sendo que duas das instituições não estabelecem nenhum critério de elegibilidade. Nas outras duas, a população atendida é aquela que se encontra em situação de vulnerabilidade social ou vivenciando riscos pessoais.

Os objetivos gerais destas instituições foram descritos da seguinte forma pelos entrevistados (entre parênteses está quantificada a incidência da resposta)

- Garantir a cidadania de crianças e adolescentes (04);

- Promover o acesso de crianças e adolescentes à cultura e ao esporte (2);

- Garantir os direitos das crianças e adolescentes (02);

- Cumprir as determinações da Lei Orgânica da Assistência Social e do Estatuto da Criança e do Adolescente (02);

- Planejar, gerenciar e executar a política de assistência social no município (01);

- Garantir o direito à convivência familiar e comunitária das crianças e adolescentes (01);

- Oferecer abrigo a crianças e adolescentes em situação de risco social ou pessoal (01).

Os entrevistados das quatro instituições que participaram da pesquisa pontuam que estabelecem parcerias com outras entidades, seja através do financiamento dos recursos ou de articulação das ações.

Em relação ao Conselho Tutelar, os representantes das quatro instituições afirmam que encaminham e recebem encaminhamento do referido órgão. Dois entrevistados destacam o procedimento de discussão de casos junto aos Conselheiros.

Sobre o financiamento de recursos materiais e humanos, as entidades informam que recebem verbas dos governos municipal, estadual e federal, de acordo com o Programa ou Projeto implementado. Em três casos o repasse advém do Fundo Municipal e em dois o repasse se dá através do estabelecimento de convênios.

\section{Considerações}

O universo desta pesquisa se constituiu de 65\% das instituições cadastradas no Conselho Municipal dos Direitos da Criança e do Adolescente (CMDCA).

Observa-se, a partir deste universo, que $82 \%$ da rede de políticas de atenção à infância e juventude do município é formada, quantitativamente, por entidades não-governamentais.

É sabido que, a partir da década de 1990, o processo de reestruturação produtiva, levada a cabo pela política neo-liberal, interfere diretamente na organização do Estado Brasileiro e conseqüentemente das políticas sociais. A máxima do "Estado mínimo" impôs a lógica da redução de gastos públicos. Tal processo acabou por devolver a "responsabilidade" de enfrentamento da questão social para a sociedade civil. Neste contexto, assistiu-se a proliferação de entidades não governamentais, que assumem a execução de projetos e programas sociais.

Verifica-se que das instituições não-governamentais que se constituíram como universo da pesquisa, 57,8\% foram inauguradas depois da promulgação do Estatuto da 
Criança e do Adolescente (1990). Destaca-se que esta lei é considerada uma conquista da mobilização do movimento social e popular na década de 80 e um avanço histórico na garantia dos direitos da população infanto-juvenil. A lei, baseada na Doutrina da Proteção Integral impõe uma nova lógica para a organização das políticas de atenção à infância. Tais políticas, dentre outros, recebem o status de direito do cidadão e dever do Estado.

Assim, espera-se que os objetivos das instituições que se propõe a desenvolver políticas sociais para esta parcela da população estejam em consonância com a letra legal, materializando a lógica do ECA em suas ações.

Observa-se, a partir do discurso da maioria dos entrevistados das Organizações Não Governamentais, que a lógica que produzem os mais variados objetivos das instituições (vide tabela $\mathrm{n}^{0} 1$ ), estão associados a padrões tradicionais de organização das políticas sociais. Considera-se como padrão tradicional aquele construído historicamente no Brasil, que, em linhas gerais, identifica as políticas sociais como benesse e caridade de seus agentes.

Constata-se que os princípios e diretrizes do ECA aparecem no discurso da maioria dos entrevistados pertencentes as políticas publicas do município, indicando que a letra legal tem sido considerada no processo de organização de tais políticas.

Verifica-se, a partir do universo pesquisado, que a maioria dos serviços prestados pelas instituições, se concentram no campo das políticas de assistência social, caracterizados sob o regime de orientação e apoio sócio-familiar e apoio sócio-educativo em meio aberto. Este dado pode sugerir que é a condição de vulnerabilidade social da população infantojuvenil que vem sendo considerada como objeto de intervenção da maioria das instituições que compõe o universo da pesquisa.

Em relação à existência de articulação entre as instituições, que configura, de fato, a noção de rede de atenção a crianças e adolescentes, observa-se que, das entidades nãogovernamentais, $47 \%$ dos entrevistados identificam que as parcerias acontecem no plano do financiamento para execução dos serviços; $26 \%$ identificam que a articulação se dá nos momentos que encaminham a população para os diversos serviços existentes no território; $15 \%$ declaram que não mantém nenhum tipo de parceria. Em $10 \%$ do universo pesquisado, o dado não foi obtido.

As entidades governamentais também identificam que a articulação entre os serviços se processa através do financiamento ou do encaminhamento de demandas.

Vale registrar que nenhum dos entrevistados cita como alvo do processo de articulação das instituições o planejamento conjunto de suas políticas; planejamento este que poderia estar relacionado, por exemplo, a identificação de demandas, feituras de diagnósticos, organização de fluxos, otimização de ações e recursos.

O debate, neste momento, pode ser remetido para a questão da pulverização de recursos e sobreposição das ações das diversas instituições, que dificultam a construção de uma rede de atenção que se organiza a partir de um diagnostico que retrate as reais demandas da população infanto-juvenil, que vivencia graves e complexas situações de risco social e pessoal.

Corrobora para esta analise a baixa participação das entidades nas Assembléias do Conselho Municipal dos Direitos da Criança e do Adolescente (66,6\% dos entrevistados das entidades que não tem assento no CMDCA declararam que nenhum de seus membros participa das Assembléias).

Observa-se, conforme declarado, que a relação estabelecida por 86,9\% das instituições com o Conselho Tutelar se configura através dos encaminhamentos e/ou recebimentos de casos. Deste universo, $15 \%$ dos entrevistados destacam que construíram espaço para discussão dos casos, mantendo contato direto com os Conselheiros. Verifica-se que $13 \%$ dos entrevistados afirmam que não mantém nenhum tipo de relação com o referido órgão. Nenhuma das instituições cita a utilização do Conselho Tutelar como fonte de informação 
para a organização de suas políticas, tendo em vista que o órgão concentra os dados sobre a população infanto-juvenil cujos direitos são violados.

Na perspectiva de finalizar as considerações apresentadas, vale registrar que a presente pesquisa deve ser considerada como um pequeno ensaio acadêmico que não se propôs a aprofundar o debate sobre o tema, mas apenas iniciá-lo. Muitas outras questões devem ser formuladas para a realização de novas pesquisas sobre a temática. Esperamos que o debate travado neste momento seja utilizado da melhor forma possível, na perspectiva de contribuir para o processo de construção de representações sobre políticas sociais que assumam como referencia o paradigma de garantia de direitos à população infanto-juvenil.

\section{Referências}

BARISON, M. Disciplina ou Cidadania? O Estatuto da Criança e do Adolescente e as Representações Sociais dos agentes sociais de um abrigo. Revista O Social em Questão v.2 n.2, Rio de Janeiro, 1997.

FREITAS, M. (org). História Social da Infância no Brasil. 5 ed. São Paulo: Cortez, 2003.

GENTILI, P. e SADER, EMIR. Pós-neoliberalismo: As Políticas Sociais e o Estado Democrático. Rio de Janeiro: Paz e Terra, 1995.

HARVEY, D. Condição Pós-Moderna. 11 ed. São Paulo: Loyola, 2002.

IAMAMOTO, M. O Serviço Social na Contemporaneidade: Trabalho e Formação Profissional. 3 ed. São Paulo: Cortez, 2000.

LEAL, M., MATOS, M. e SALES, M (org). Política Social, Família e Juventude: Uma Questão de Direitos. São Paulo: Cortez, 2004.

MINAYO, M. O Desafio do Conhecimento. 3 ed. São Paulo - Rio de Janeiro: HUCITEC ABRASCO, 1994.

\section{Anexos}

\subsection{Listagem das Instituições}

\subsubsection{Nome da Instituição: Fundação CSN}

Endereço: Rua 104 n $^{\circ} 150$ - Laranjal

Programas Destinados a Infância e Juventude:

- Projeto Garoto Cidadão;

- Projeto Viva Vôlei;

- Projeto Badmintow.

Público Alvo:

- Crianças e Adolescentes em situação de vulnerabilidade social;

- Faixa etária de 08 aos 18 anos;

- Masculino e feminino.

Linhas de Ação:

- Políticas de Assistência Social; 
- Apoio sócio-educativo em meio aberto.

Atividades Desenvolvidas:

- Esporte e Lazer

5.1.2 Nome da Instituição: Lions Clube de Volta Redonda

Endereço: Av. Mariana do Carmo Nogueira Guedes nº 289 - Vila Mury

Programas Destinados a Infância e Juventude:

- Edificação de Escolas;

- Inserção no mercado de trabalho (em parceria com o CAMP - Circulo de Amigos do Menor Patrulheiro);

- Campanha Projeto Saúde e Solidariedade (em parceria com UniFoa).

Público Alvo:

- Crianças e Adolescentes em situação de vulnerabilidade social;

- Masculino e feminino.

Linhas de Ação:

- Políticas de Assistência Social;

- Apoio sócio-educativo em meio aberto.

Atividades Desenvolvidas:

- Profissionalizante;

- Educação em saúde.

5.2.3 Nome da Instituição: Núcleo de Prevenção e Assistência a Dependentes Químicos e seus familiares

Endereço: Rua 756 n 225 - Casa de Pedra

Programas Destinados a Infância e Juventude:

- Assistência a Dependentes Químicos e seus familiares

Público Alvo:

- Adolescentes;

- Faixa etária: a partir de 14 anos;

- Masculino.

Linhas de Ação:

- Políticas de atenção em saúde;

- Orientação e Apoio sócio-familiar.

Atividades Desenvolvidas:

- Triagem, avaliação e Encaminhamento para Clinica de Tratamento em Cambuquira (Minas Gerais).

5.1.4 Nome da Instituição: CAMP (Circulo de Amigos do Menor Patrulheiro)

Endereço: Av. Mariana do Carmo Nogueira Guedes nº 289 - Vila Mury

Programas Destinados a Infância e Juventude:

- Aprendizagem;

- Estágio.

Público Alvo:

- Adolescentes;

- Faixa Etária de 15 a 18 anos;

- Masculino e Feminino.

Linhas de Ação:

- Políticas de Assistência Social;

- Apoio sócio-educativo em meio aberto. 
Atividades Desenvolvidas:

- Preparação de adolescentes aprendizes para inserção de estagiários no mercado de trabalho, através de empresas conveniadas.

\subsubsection{Nome da Instituição: Pastoral da Criança}

Endereço: Rua $4 n^{\circ} 213$ - Conforto

Programas Destinados a Infância e Juventude:

- Prevenção da desnutrição infantil;

Público Alvo:

- Crianças em situação de vulnerabilidade social;

- Faixa etária de 0 a 06 anos;

- Masculino e feminino;

- Gestantes.

Linhas de Ação:

- Políticas de Assistência Social;

- Políticas de Atenção em Saúde;

- Orientação e apoio sócio-familiar.

Atividades Desenvolvidas:

- Identificação de gestantes e crianças que vivenciam situações de vulnerabilidade para saúde;

- Cadastramento de gestantes de crianças com baixo peso;

- Acompanhamento mensal do desenvolvimento de gestantes e crianças através de visita domiciliar.

5.1.6 Nome da Instituição: Associação Beneficente Evangélica

Endereço: Av. Retiro n ${ }^{\circ} 3294$ - Retiro

Programas Destinados a Infância e Juventude:

- Creche e Reforço escolar;

- Atenção em saúde;

- Auxilio Material.

Público Alvo:

- Crianças em situação de vulnerabilidade social;

- 1 ano e seis meses a 10 anos;

- Masculino e feminino.

Linhas de Ação:

- Política de assistência social e educação;

- Apoio sócio-educativo em meio aberto.

Atividades Desenvolvidas:

- Atendimento pedagógico e de recreação;

- Atendimento Odontológico;

- Distribuição de alimentação, medicação etc.

5.1.7 Nome da Instituição: Serviços de Obras Sociais (SOS)

Endereço: Rua Pompeu n 235 - Voldac

Programas Destinados a Infância e Juventude:

- Creche

Público Alvo:

- Crianças em situação de vulnerabilidade social;

- Faixa etária de 0 a 05 anos; 
- Masculino e feminino.

Linhas de Ação:

- Política de assistência social e educação;

- Apoio sócio-educativo em meio aberto.

Atividades Desenvolvidas:

- Atendimento pedagógico e de recreação;

\subsubsection{Nome da Instituição: União Espírita de Advertência Fraternal (UEAF)}

Endereço: Rua Arthur Luiz Correa ${ }^{\circ} 55$ Voldac

Programas Destinados a Infância e Juventude:

- Assistência Religiosa;

- Educação em Saúde;

- Auxílio material.

Público Alvo:

- Crianças e Adolescentes em situação de vulnerabilidade social;

- Faixa Etária de 0 a 18 anos;

- Masculino e Feminino.

Linhas de Ação:

- Política de Assistência Social;

- Orientação e apoio sócio-familiar.

Atividades Desenvolvidas:

- Palestras educativas;

- Distribuição de recursos materiais (alimentação, cobertores, medicação etc);

- Orientação e estudo espiritual.

5.1.9 Nome da Instituição: Casa do Bom Samaritano

Endereço: Via A1 n ${ }^{0} 51$ São Sebastião

Programas Destinados a Infância e Juventude:

- Creche;

- Reforço Escolar;

- Projeto Garoto Cidadão (parceria com Fundação CSN);

- Auxilio Material.

Público Alvo:

- Crianças e adolescentes em situação de vulnerabilidade social;

- Faixa etária de 01 a 15 anos;

- Masculino e Feminino.

Linhas de Ação:

- Política de assistência social e educação;

- Apoio sócio-educativo em meio aberto;

- Orientação e apoio sócio-familiar.

Atividades Desenvolvidas:

- Atendimento pedagógico e de recreação;

- Distribuição de recursos materiais.

5.1.10 Nome da Instituição: Associação da Criança e do Adolescente (ACA) Endereço: Rua $07 \mathrm{n}^{\circ} 59$ - Vale Verde

Programas Destinados a Infância e Juventude:

- Esporte (Projeto Abrindo Caminhos, convênio com Ministério do Esporte); 
- Cultural (Projeto Cesta Básica Cultural, convênio com Ministério da Cultura);

- Trabalho, Emprego e Renda (Programa Nacional de Estímulo ao Primeiro Emprego, convênio com Ministério do Trabalho e Emprego).

Público Alvo:

- Crianças e Adolescentes em situação de vulnerabilidade social;

- Faixa Etária de 0 a 18 anos;

- Masculino e Feminino.

Linhas de Ação:

- Política de Assistência Social;

- Apoio sócio-educativo em meio-aberto.

Atividades Desenvolvidas:

- Esporte, lazer e cultura;

- Participação em campeonatos esportivos, festas populares e diversos eventos;

- Preparação e inserção no mercado de trabalho de jovens.

\subsubsection{Nome da Instituição: Cruz Vermelha Brasileira}

Endereço: Rua 40 n $^{\circ} 13$ - Vila Santa Cecília

Programas Destinados a Infância e Juventude:

- Projeto Fisioterapia para Todos;

- Atendimento Psicológico;

- Cursos de Primeiros Socorros.

Público Alvo:

- Crianças e Adolescentes em situação de vulnerabilidade social;

- Faixa etária 0 a 18 anos;

- Adolescentes com mais de 15 anos (Curso de Primeiros Socorros);

- Masculino e Feminino.

Linhas de Ação:

- Políticas sociais básicas (saúde);

- Orientação e apoio sócio-familiar.

Atividades Desenvolvidas:

- Atendimento fisioterápico;

- Atendimento psicológico;

- Participação em Campanhas de Prevenção em Saúde.

\subsubsection{Nome da Instituição: Associação Assistencial Frutificando}

Endereço: Av. Beira Rio no 444 - Niterói

Programas Destinados a Infância e Juventude:

- Projeto El Shaday;

- Menor Aprendiz;

- Curso de Informática.

Público Alvo:

- Crianças e Adolescentes em situação de vulnerabilidade social;

- Faixa etária de 0 a 18 anos;

- Masculino e feminino.

Linhas de Ação:

- Política de Assistência Social;

- Apoio sócio-educativo em meio-aberto.

Atividades Desenvolvidas: 
- Auxilio material (distribuição de leite; cobertores, alimentos);

- Assistência jurídica;

- Encaminhamento de adolescentes para primeiro emprego;

- Cursos de informática.

5.1.13 Nome da Instituição: Associação dos Pais e Amigos do Deficiente Físico (APADEFI)

Endereço: Av. Marechal Euclides Figueiredo no 350 - Retiro

Programas Destinados a Infância e Juventude:

- Assistência social;

- Tratamento psico, fono e fisioterápico.

Público Alvo:

- Crianças e adolescentes em situação de vulnerabilidade social;

- Portadores de deficiência física;

- Faixa etária de 0 a 18 anos;

- Masculino e feminino.

Linhas de Ação:

- Políticas de assistência social;

- Políticas sociais básicas (saúde);

- Orientação e apoio sócio-familiar.

Atividades Desenvolvidas:

- Atendimento Psicológico;

- Atendimento Fono e Fisioterápico;

- Atendimento de hidroterapia;

- Atendimento a famílias;

- Cessão de próteses, cadeiras de rodas, banheiras etc.

\subsubsection{Nome da Instituição: Centro Social Santa Cecília}

Endereço: Rua 31 n 146 Vila Santa Cecília

Programas Destinados a Infância e Juventude:

- Creche Comunitária

Público Alvo:

- Crianças e Adolescentes em situação de vulnerabilidade social;

- Faixa etária e 01 ano e oito meses a 04 anos;

- Masculino e feminino.

Linhas de Ação:

- Política de assistência social e educacional;

- Apoio sócio-educativo em meio aberto;

- Orientação e apoio sócio-familiar.

Atividades Desenvolvidas:

- Atendimento pedagógico e de recreação.

5.1.15 Nome da Instituição: Rotary Clube de Volta Redonda

Endereço: Rua Rotary Internacional no 45 - Jardim Primavera

Programas Destinados a Infância e Juventude:

- Atividades de lazer realizadas eventualmente;

- Projetos Comunitários;

- Creche. 
Público Alvo:

- Crianças e adolescentes em situação de vulnerabilidade social;

- Faixa etária de 06 meses a 10 anos;

- Masculino e Feminino.

Linhas de Ação:

- Política de Assistência social e educacional

Atividades Desenvolvidas:

- Festas em datas comemorativas;

- Atendimento pedagógico e recreativo.

\subsubsection{Nome da Instituição: Casa da Criança e do Adolescente}

Endereço: Rua 21 n $^{0} 34$ - Vila Santa Cecília

Programas Destinados a Infância e Juventude:

- Programa de Atendimento a Criança e Adolescente Vítima de Maus-Tratos

Público Alvo:

- Crianças e adolescentes vítimas de violência doméstica;

- Faixa etária: 0 a 18 anos incompletos;

- Masculino e feminino.

Linhas de Ação:

- Políticas de Assistência social;

- Orientação e apoio sócio-familiar.

Atividades Desenvolvidas:

- Diagnostico de situações de violência doméstica;

- Encaminhamento das famílias para rede de atendimento, conforme demanda;

- Suporte técnico para Órgãos de Proteção a Infância e Adolescência.

\subsubsection{Nome da Instituição: Lar Espírita Irmã Zilá}

Endereço: Rua L $\mathrm{n}^{\circ} 76$ Belmonte

Programas Destinados a Infância e Juventude:

- Creche;

- Auxilio Material;

- Educação em Saúde;

- Atendimento médico, odontológico, fonoaudiólogo, psicológico.

Público Alvo:

- Crianças e Adolescentes em situação de vulnerabilidade social;

- Faixa etária de 04 meses a 12 anos;

- Masculino e feminino.

Linhas de Ação:

- Política de assistência social e educação;

- Política social básica (saúde);

- Orientação e apoio sócio-familiar;

- Apoio sócio-educativo em meio aberto.

Atividades Desenvolvidas:

- Distribuição de recursos materiais;

- Atendimento pedagógico e recreação;

- Atendimento do médico, fonoaudiólogo, psicólogo e dentista;

- Orientação espiritual. 
5.1.18 Nome da Instituição: Associação dos Pais e Amigos dos Excepcionais (APAE)

Endereço: Rua 60 n $^{0} 1790$ - Sessenta

Programas Destinados a Infância e Juventude:

- Atendimentos clínicos, educacionais e de assistência social.

Público Alvo:

- Crianças e Adolescentes portadores de deficiência mental e outras;

- Faixa Etária: a partir de 01 mês de nascido;

- Masculino e Feminino.

Linhas de Ação:

- Políticas Sociais básicas (saúde);

- Políticas de Assistência social;

- Orientação e apoio sócio-familiar.

- Apoio sócio-educativo em meio aberto

Atividades Desenvolvidas:

- Estimulação e Desenvolvimento;

- Ensino Especializado;

- Ensino Profissionalizante.

5.1.19 Nome da Instituição: Instituto de Desenvolvimento e Estudos, Ações e Implementações Sociais (IDEAIS)

Endereço: Rua 27 n 56 - Vila Santa Cecília

Programas Destinados a Infância e Juventude:

- Programa Aluno Residente

- GAIA;

- CURUMIM;

- DESENVOLVER.

Público Alvo:

- Crianças e Adolescentes em situação de vulnerabilidade social;

- Faixa Etária de 06 a 14 anos;

- Masculino e Feminino.

Linhas de Ação:

- Políticas sociais básicas (tratamento e prevenção em dependência química);

- Política de assistência social;

- Abrigo;

- Apoio sócio-educativo em meio aberto;

- Orientação e apoio sócio-familiar.

Atividades Desenvolvidas:

- Atendimento interdisciplinar em dependência química;

- Abrigamento de crianças e adolescentes;

- Atividades sócio-educativas e pedagógicas nas comunidades.

5.1.20 Nome da Instituição: Secretaria Municipal de Ação Comunitária (SMAC)

Endereço: Rua Paulo Leopoldo Marçal nº 103 -Aterrado

Programas Destinados a Infância e Juventude:

- Vem Pro Centro;

- Erradicação do Trabalho Infantil;

- Informática Educativa;

- Espaço de Convivência; 
- Agente Jovem;

- Sentinela;

- Brinquedoteca.

Público Alvo:

- Crianças e Adolescentes em situação de vulnerabilidade e risco social;

- Faixa Etária de 0 a 18 anos;

- Masculino e feminino.

Linhas de Ação:

- Política de assistência social;

- Orientação e apoio sócio-familiar;

- Apoio sócio-educativo em meio aberto.

5.1.21 Nome da Instituição: Secretaria Municipal de Cultura

Endereço: Av. Alexandre Polastri Filho nº 791 - Ilha São João

Programas Destinados a Infância e Juventude:

- Palco Sobre Rodas;

- Teatro infantil;

Público Alvo:

- Crianças e Adolescentes;

- Faixa Etária: indeterminada;

- Masculino e Feminino.

Linhas de Ação:

- Políticas Sociais Básicas;

Atividades Desenvolvidas:

- Apresentações de teatro, danças, cinemas nas comunidades.

5.1.22 Nome da Instituição: Secretaria Municipal de Esporte Endereço: Av. Alexandre Polastri Filho nº 791 - Ilha São João

Programas Destinados a Infância e Juventude:

- Colônia de Férias;

- Segundo Tempo;

- Atividades Recreativas;

Público Alvo:

- Crianças e Adolescentes matriculadas nas Escolas da Rede Publica;

- Faixa Etária: 07 aos 17 anos;

- Masculino e Feminino.

Linhas de Ação:

- Políticas Sociais Básicas;

- Apoio sócio educativo em meio aberto;

Atividades Desenvolvidas:

- Oferta de atividades de esporte e lazer em diversas comunidades.

5.1.23 Nome da Instituição: Fundação Beatriz Gama

Endereço: Estrada Francisco Sabóia $n^{\circ} 3000$ - Retiro

Programas Destinados a Infância e Juventude:

- Abrigo Descentralizado;

- Capacitação Profissional;

- Programa de Educação e Assistência ao Adolescente; 
- Programa Família em Ação;

- Programa Criança Cidadã;

- Programa de Erradicação do Trabalho Infantil.

Público Alvo:

- Crianças e Adolescentes em situação de risco social e pessoal;

- Faixa Etária: 0 a 18 anos;

- Masculino e Feminino.

Linhas de Ação:

- Política de Assistência;

- Proteção Jurídico-social;

- Orientação e Apoio sócio-familiar;

- Abrigo.

\subsection{Os alunos pesquisadores}

Aline Nascimento Querino; Ana C. A. M. Cardoso; Ana Paula de Souza; Andréia Silvério Tomé; Camila Lopes de Souza; Camila Medeiros; Danniely G. Viana; Deivison P. S. Souza; Eliana Carmem da Silva; Erinete C. dos S. Gomes; Elaine Ribeiro; Fátima M. F.R. Coelho; Gesiane L. Jorge; Gilvane M. Ribeiro; Gisele Aparecida T. Netto; Jaqueline M. dos Santos; Josiele Bom da Silva; Josilene da Rocha; Juliana M. Gomes; Kamila M. B. Barbosa; Letícia das G. de Paula; Leila T. Pinto Carmo; Ligia P. S. Martins; Liliane R. Ribeiro; Lourdes Barbosa; Luciene F. Berbet; Lucimaura Amaral; Madalena G. Tinoco; Mariana C. Barbosa; Maria das D. R. Fontes; Maria Helena B. Franco; Mary Lucia F. R. Soares; Natalia G. Alves; Neuzi Santos; Paulo José Soares; Polyana de Oliveira Souza; Roberta Braz; Shirlane Cassiano Vieira; Silvia H. Fonseca; Simone Moreira Castro; Sintia T.S. Dias; Talita da Silva Terra; Valdinéia de S. Andrade; Vera Lucia de C. Inácio.

\section{Informações bibliográficas:}

Conforme a NBR 6023:2002 da Associação Brasileira de Normas Técnicas (ABNT), este texto científico publicado em periódico eletrônico deve ser citado da seguinte forma: BARISON, Monica Santos. As Políticas de Atenção à Infância e Juventude no Município de Volta Redonda: um Mapeamento das Instituições Inscritas no Conselho Municipal dos Direitos da Criança e do Adolescente. Cadernos UniFOA, Volta Redonda, ano 1, n ${ }^{\circ}$. 1, jul. 2006. Disponível em: <http://www.unifoa.edu.br/pesquisa/caderno/edicao/01/83.pdf> 